\title{
Role of LPS length in clearance rate of bacteria from the bloodstream in mice
}

\author{
Akira Ohno, ${ }^{1}$ Yosikazu Isii, ${ }^{1}$ Kazuhiro Tateda, ${ }^{1}$ Tetuya Matumoto, ${ }^{1}$ \\ Shuici Miyazaki, ${ }^{1}$ Shinichi Yokota ${ }^{2}$ and Keizo Yamaguchi ${ }^{1}$
}

Author for correspondence: Akira Ohno. Tel: +8133762 4151 ext. 2397. Fax: +81354935415.

1 Department of

Microbiology, Toho

University School of

Medicine, 5-21-16 Omori-

Nishi, Ota-Ku, Tokyo 143,

Japan

2 Sumitomo Pharmaceuticals Research Centre,

Konohana-ku, Osaka 554, Japan
Strains of Pseudomonas aeruginosa isolated from patients with cystic fibrosis (CF) never spread systemically. This may be due to serum sensitivity since these strains are very sensitive to complement-mediated bactericidal activity. A serum-resistant mutant, P. aeruginosa TUM3 HSR, was obtained from serumsensitive strain TUM3 from a CF patient in order to clarify the mechanism of failure of systemic spread. LPS profiles on silver-stained gels and immunological analysis revealed that a long 0-polysaccharide side chain was overproduced on the LPS molecules of TUM3 HSR as compared with the LPS of TUM3. The clearance rate from the bloodstream in mice was compared in the two strains. The number of TUM3 bacteria in $1 \mathrm{ml}$ of blood, $10 \mathrm{~min}$ after injection into the tail vein, significantly decreased from $1.7 \times 10^{8}$ to $3.7 \times 10^{5}$ c.f.u. $\mathrm{ml}^{-1}$. In contrast, TUM3 HSR was not eliminated during the same period (decrease from $1.9 \times 10^{8}$ to $3.4 \times 10^{7} \mathrm{c} . f . u . ~ \mathrm{ml}^{-1}$ ). Interestingly, these isogenic strains were not killed by $\mathbf{4 0} \%$ murine serum, probably reflecting immaturity of the complement-mediated killing system in mice. These results pointed to a correlation between LPS structure and blood clearance rate in mice. This was confirmed by examining blood clearance kinetics using the smooth-LPS strain Salmonella typhimurium LT2 and LPS-deficient mutants derived from it. S. typhimurium LT2 resisted blood clearance while the LPS-deficient mutants were cleared rapidly. None of the $S$. typhimurium strains were killed by murine serum. The number of $P$. aeruginosa TUM3 and 5 . typhimurium LPS-deficient mutants trapped in the liver following injection into the peripheral circulation was greater than that of their counterparts. These results indicate that the long O-polysaccharide side chain of LPS may play a crucial role in evading phagocytosis by the reticuloendothelial system (RES), and therefore, may control the establishment of systemic infection by Gram-negative bacteria. The interaction between complement $\mathrm{C} 3$ on bacteria and $\mathrm{C} 3$ receptors on macrophages may also be involved in the trapping mechanism by the RES. It was expected that the level of $\mathrm{C} 3$ bound on the cell surface would be higher in $P$. aeruginosa TUM3 or the LPS-deficient mutants derived from S. typhimurium LT2. However, our flow-cytometric results demonstrated that the level of C3 was almost identical in isogenic strains.

Keywords: lipopolysaccharide, blood clearance, complement, Pseudomonas aeruginosa

\section{INTRODUCTION}

Patients with cystic fibrosis (CF) develop repetitive infection caused by Pseudomonas aeruginosa during progression of the disease, but the infection is limited to the lung and does not spread to the blood. This is in contrast to several other classes of patients infected with $P$. aeruginosa that frequently develop severe systemic infections. It is still unclear why $P$. aeruginosa colonizing the lungs of CF patients never spreads systemically. Several lines of evidence suggest that serum sensitivity may play
Abbreviations: CF, cystic fibrosis; CR3, complement receptor type 3; FITC, fluorescein isothiocyanate; FHS, fresh human serum; FMS, fresh mouse serum; KDO, 2-keto-3-deoxyoctonic acid (3-deoxy-D-manno-2-octulosonic acid); RES, reticuloendothelial system. 
an important role in this process. For example, isolates of $P$. aeruginosa from patients with $\mathrm{CF}$ are usually sensitive to human complement-mediated bactericidal systems (Thomassen \& Demko, 1981). This is in contrast to isolates from patients with bacteraemia known to be resistant to serum bactericidal activity (Schiller \& Hatch, 1983).

The long-chain O-polysaccharide portion of lipopolysaccharide (LPS) acts as a barrier for complementmediated killing in Gram-negative bacteria, in addition being responsible for the $\mathrm{O}$ specificity ( $\mathrm{O}$ antigen) that determines the serotype of a particular strain (Taylor, 1983; Palomar et al., 1993). P. aeruginosa is capable of producing LPS with two different polysaccharides on the same LPS molecule (Hatano et al., 1993), termed A- and B-bands, that have been identified in PAO1 (Rivera $e$ t al., 1988; Rivera \& McGroarty, 1989). The B-band is composed of LPS with a long O-polysaccharide side chain and is responsible for $\mathrm{O}$ specificity. In contrast, the Aband LPS has only a short neutral polysaccharide side chain, composed mainly of D-rhamnan (Arsenault et al., 1991; Coyne et al., 1994), which is a common antigen shared among $P$. aeruginosa strains (Lam et al., 1989; Yokota et al., 1990). Most isolates from CF patients have lost the high molecular mass polysaccharide B-band (Lam et al., 1989). Therefore, these isolates are sensitive to human serum bactericidal activity.

We previously compared the bactericidal activity of human and murine (ICR, male, 4 weeks) serum against $P$. aeruginosa strains from CF patients (Ohno et al., 1992). Most strains were sensitive to human serum; however, all strains were unexpectedly resistant to murine serum. Interestingly, in spite of their resistance to murine serum, the human-serum-sensitive strains were rapidly eliminated from the bloodstream after injection into the tail vein of mice, whereas the human-serum-resistant strains were not eliminated (unpublished data). Thus, it was considered that mechanisms other than serum sensitivity might play a role in blood clearance, at least in mice. On the other hand, phagocytosis by the reticuloendothelial system (RES) is an important factor involved in blood clearance as well as the serum bactericidal system. Complement component $\mathrm{C} 3$, bound on the bacterial surface, particularly LPS, plays an important role in phagocytosis by binding to $\mathrm{C} 3$ receptors such as $\mathrm{CR} 1$ or $\mathrm{CR} 3$ on phagocytic cells. It is also known that the long O-polysaccharide chains of LPS may prevent binding of C3 to LPS ('Taylor et al., 1983; Schiller \& Joiner, 1986; Arsenault et al., 1991; Merino et al., 1992). Thus, the relationship between the length of the LPS side chain and binding ability of C3 may explain the difference in blood clearance of strains with or without a long polysaccharide chain.

To explore these issues, we isolated a serum-resistant mutant of $P$. aeruginosa strain TUM3. In this derivative the biosynthesis of long O-polysaccharide chains on the LPS molecule was increased. Using these isogenic strains, in addition to Salmonella typhimurium LT2 and its LPSdeficient mutants, we investigated the role of LPS length and phagocytosis in blood clearance in mice.

\section{METHODS}

Bacterial strains and growth conditions. The strains used in this study are shown in Table 1 . The mucoid $P$. aeruginosa strain TUM3, isolated from the sputum of a CF patient, was kindly provided by Dr M. I. Marks, Miller Children's Hospital, Long Beach, CA, USA. $P$. aeruginosa TUM3 HSR was isolated from TUM3 as a serum-resistant mutant using the method of Shiller et al. (1984). Briefly, P. aeruginosa was incubated at $35^{\circ} \mathrm{C}$ for $18 \mathrm{~h}$ in brain-heart infusion (BHI, Difco) broth containing fresh human serum (FHS) in increasing concentrations $(0.31-40 \%$; by the twofold dilution method). Cells grown in the broth, including FHS of the highest concentration, were transferred to the next set and the same procedure was repeated three times. Finally, cells grown on a medium including $40 \%$ FHS were selected as serum-resistant mutants. Serotyping was carried out by the slide agglutination method with a serotype grouping kit (Mei-assay; Meiji Seika). S. typhimurium LT2 and its LPSdeficient mutants (Lindberg \& Hellerqvist, 1971; Roantree et al., 1977) were kindly provided by Professor T. Sawai, Faculty of Pharmaceutical Sciences, Chiba University, Chiba, Japan. Unless otherwise stated, organisms were grown at $35^{\circ} \mathrm{C}$ on $\mathrm{BHI}$ agar.

Laboratory animals. SPF male ICR mice (Japan Charles River), weighing 19-21 g, were used for blood clearance assays and serum bactericidal microassays.

Blood clearance of bacteria in mice. Colonies grown on a $\mathrm{BHI}$ agar plate for $18 \mathrm{~h}$ at $35^{\circ} \mathrm{C}$ were suspended in saline and adjusted to $10^{8}$ c.f.u. $\mathrm{ml}^{-1}$. Five mice were used in each group; they were injected in the tail vein with $0.2 \mathrm{ml}$ of the bacterial suspension. Following anaesthesia of the animal, $30 \mu \mathrm{l} \mathrm{blood}$ was obtained from the retro-orbital plexus using disposable heparinized capillary tubes, 10 and $30 \mathrm{~min}$ after injection, and mixed with $270 \mu \mathrm{l}$ saline. At the same time, the liver was removed aseptically, and a volume of saline equal to its weight was added before homogenization in a Teflon homogenizer. The blood suspension and homogenized liver were diluted in saline using the serial tenfold dilution method. One hundred microlitres of each dilution was plated on a modified Drigalski agar (Eiken Chemical). After overnight culture at $35^{\circ} \mathrm{C}$, bacterial counts were calculated in c.f.u. $(\mathrm{ml} \text { blood })^{-1}$ or in c.f.u. ( $\mathrm{g}$ liver $)^{-1}$. The control values were calculated by estimating the total blood volume as $8 \%(\mathrm{v} / \mathrm{w})$ of the body weight of each mouse used (Leunk \& Moon, 1982). The ratio of bacteria in the liver to that in the blood was defined as the phagocytosis index of the RES.

Complement killing microassay. Fresh serum was obtained from healthy volunteers and from mice. Colonies grown for $18-24 \mathrm{~h}$ on a BHI agar plate were suspended in phosphatebuffered saline (PBS) and washed three times with PBS. The bacterial concentration was diluted in PBS to a final value of about $10^{4}$ or $10^{8}$ c.f.u. $\mathrm{ml}^{-1}$. One hundred microlitres of bacterial suspension was mixed with the same volume of $20 \%$ FHS or $80 \%$ fresh mouse serum (FMS). The mixture was incubated at $37^{\circ} \mathrm{C}$ for $2 \mathrm{~h}$, and diluted to $10^{-1}$ to $10^{-3}$. The percentage of surviving bacteria was determined by plating $100 \mu \mathrm{l}$ of the original and diluted samples onto BHI agar plates. The number of c.f.u. $\mathrm{ml}^{-1}$ was determined after overnight incubation at $35^{\circ} \mathrm{C}$ and compared with that of control, containing PBS in place of FHS and FMS.

Determination of $\mathrm{C}_{3}$ binding to the surface of bacteria. Bacterial colonies grown on a BHI plate were suspended in PBS and washed three times with the same buffer. The suspension was adjusted to $\mathrm{OD}_{550} 0.4$ using a Beckman DU 640 spectrophotometer and mixed with an equal volume of FMS. After incubation at $37^{\circ} \mathrm{C}$ for $30 \mathrm{~min}$, cells were pelleted by brief 
Table 1. Bacterial strains

\begin{tabular}{|c|c|c|}
\hline Strain & Revelant characteristics* & Source or reference \\
\hline \multicolumn{3}{|l|}{$P$. aeruginosa } \\
\hline TUM3 & $\begin{array}{l}\text { Mucoid, serotype G, short-polysaccharide } \\
\text { chain LPS, serum sensitive }\end{array}$ & Cystic fibrosis \\
\hline TUM3 HSR & $\begin{array}{l}\text { Mucoid, serotype G, long-polysaccharide } \\
\text { chain LPS, serum resistant }\end{array}$ & Derivative of TUM3 \\
\hline \multicolumn{3}{|l|}{ S. typhimurium } \\
\hline LT2 & Autotroph (S) & Lindberg \& Hellerqvist (1971) \\
\hline SL1034 & $r f e-465(\mathrm{SR})$ & Roantree et al. (1977) \\
\hline TV119 & $r f b-430(\mathrm{Ra})$ & Roantree et al. (1977) \\
\hline SL733 & $r f a K(\mathrm{Rb} 1)$ & Roantree et al. (1977) \\
\hline TV160 & met $A 22$ bryB2 galT411 rfa-418 (Rb2) & Lindberg \& Hellerquist (1971) \\
\hline TV148 & $r f a-433(\mathrm{Rb} 3)$ & Lindberg \& Hellerqvist (1971) \\
\hline LT2M1 & galE (Rc) & Roantree et al. (1977) \\
\hline SL1004 & $r f b-430$ rfaG571 (Rd1) & Roantree et al. (1977) \\
\hline TA2168 & hisC3076 galE506 rfa-1009 (Re) & Lindberg \& Hellerqvist (1971) \\
\hline
\end{tabular}

*Serotyping of $P$. aeruginosa was performed using the Mey-assay monoclonal typing system (Meiji Seika). Structure of LPS (S. typhimurium): S, smooth LPS; SR, O-antigen with only one repeating unit; Ra, outer core without O-antigen; Rb1, outer core without GlcNAc; Rb2, outer core without GlcNAc-Glc; Rb3, outer core without GlcNAc-Glc-Gal; Rc, outer core without GlcNAc-Glc-Gal-Gal; Rd1, inner core only, without outer core; $R e$, inner core without triheptose (deep rough LPS).

Table 2. Sensitivities to human serum of $P$. aeruginosa TUM3 and TUM3 HSR, and S. typhimurium LT2 and the LPS isogenic mutants

\begin{tabular}{|c|c|c|c|c|c|}
\hline \multirow[t]{2}{*}{ Strain } & \multicolumn{3}{|c|}{$\begin{array}{c}\text { Sensitivity to } 10 \% \text { human serum (survival ratio, \%*) } \\
\text { with an inoculum of: }\end{array}$} & \multicolumn{2}{|c|}{$\begin{array}{l}\text { Sensitivity to } 40 \% \text { murine serum } \\
\text { (survival ratio, } \% * \text { ) with an } \\
\text { inoculum of: }\end{array}$} \\
\hline & $10^{4}$ & $10^{6}$ & $10^{8}$ & $10^{4}$ & $10^{6}$ \\
\hline \multicolumn{6}{|l|}{$P$. aeruginosa } \\
\hline TUM3 & $<0.03$ & $0.0006(0.0002)$ & $0.048(0.002)$ & $294(48 \cdot 4)$ & NT \\
\hline TUM3 HSR & $182(96)$ & $367(44)$ & $125(16)$ & $266(61 \cdot 9)$ & NT \\
\hline \multicolumn{6}{|l|}{ S. typhimurium $\dagger$} \\
\hline $\mathrm{LT} 2(\mathrm{~S})$ & $0.14(0.02)$ & $18 \cdot 2(2 \cdot 8)$ & $61 \cdot 8(3 \cdot 4)$ & NT & $770(286)$ \\
\hline SL1034 (SR) & $<0.01$ & $0.0008(0.0006)$ & $0.025(0.008)$ & NT & NT \\
\hline TV119 (Ra) & $0.02(0.01)$ & $0.08(0 \cdot 12)$ & $0.02(0.001)$ & NT & NT \\
\hline SL733 (Rb1) & $<0.01$ & $0.02(0.02)$ & $0.095(0.091)$ & NT & NT \\
\hline TV160 (Rb2) & $0.025(0.017)$ & $0.028(0.046)$ & $0.082(0.029)$ & NT & NT \\
\hline TV148 (Rb3) & $0 \cdot 10(0 \cdot 14)$ & $1.97(0.51)$ & $0.048(0.009)$ & NT & NT \\
\hline LT2M1 (Rc) & $<0.01$ & $<0.0005$ & $0.27(0.033)$ & NT & NT \\
\hline SL1004 (Rd1) & $0.01(0.005)$ & $<0.0006$ & $0.025(0.0002)$ & NT & NT \\
\hline TA2168 $(\mathrm{Re})$ & $<0.01$ & $<0.0006$ & $0.00007(0.00006)$ & NT & $77 \cdot 1(25 \cdot 3)$ \\
\hline
\end{tabular}

*Survival ratio (\%) for the different inoculum sizes shown was expressed as the ratio of survived cells to inoculum cell numbers after $2 \mathrm{~h}$ incubation. The figures in parentheses are standard deviations of three experiments. NT, Not tested.

†Structure of LPS (see Table 1) shown in parentheses.

centrifugation in a microcentrifuge, washed three times, and suspended in PBS. Fluorescein-conjugated goat IgG to mouse complement C3 (Organon Teknika) was added to the sus- pension at a ratio of $1: 200$ and incubated at room temperature for $30 \mathrm{~min}$ with gentle shaking. Free $\mathrm{IgG}$ was completely removed by washing with PBS and the intensity of fluorescence 
per 10000 bacterial cells in suspension was determined by flow cytometry (Becton Dickinson) using Consort 30 software.

LPS profile. LPS was isolated and purified according to the method of Darveau \& Hancock (1983). LPS bands were visualized by silver staining after SDS-PAGE in a $12.5 \%(\mathrm{w} / \mathrm{v})$ polyacrylamide gel.

Monoclonal antibodies. Monoclonal antibodies TK-5B12 (IgG), OM-1D6 and TS-1B2, were used. TK-5B12 (human IgG2), OM-1D6 (human IgM) and TS-1B2 (human IgM) recognized the serotype $G$ O-polysaccharide, the serotype $G$ core region and the $P$. aeruginosa common antigen, D-rhamnan (A-band LPS), respectively. The hybridomas producing these $\mathrm{mAbs}$ were prepared by cell fusion of pokeweed nitrogenstimulated human peripheral blood lymphocytes from healthy adult volunteers and human-mouse heteromyeloma SHM-D33 (ATCC CRL 1668) using polyethylene glycol (Yokota et al., 1989). The hybridomas were cultured in serum-free medium Celgrosser H (Sumitomo Pharmaceuticals). The mAbs were purified from the concentrated culture supernatant by gel filtration chromatography on Superose 6 (Pharmacia) for IgM, and by Protein A-Cellulofine (Seikagaku Kogyo) chromatography for IgG.

Immunoblotting. Western blotting was carried out as described previously (Yokota et al., 1989). Briefly, after SDS-PAGE, LPS on gel was transferred to a PVDF membrane with a semi-dry electroblotting apparatus. The membrane was blocked with $2 \%$ $(\mathrm{w} / \mathrm{v})$ casein in PBS, and subsequently incubated with $\mathrm{mAb}$ $\left(1 \mu \mathrm{g} \mathrm{ml}^{-1}\right)$ and alkaline-phosphatase-conjugated goat anti-human IgG antibody (1000-fold dilution). Specific binding was detected with sodium 5-bromo-4-chloro-3-indoyl phosphate $\left(0.15 \mathrm{mg} \mathrm{ml}^{-1}\right)$ and nitroblue tetrazolium chloride $\left(0.3 \mathrm{mg} \mathrm{ml}^{-1}\right)$ in $100 \mathrm{mM}$ sodium carbonate buffer ( $\mathrm{pH} \mathrm{9.8)} \mathrm{containing} 1 \mathrm{mM}$ $\mathrm{MgCl}_{2}$.

ELISA. The methods for ELISA and preparation of bacterialcell-coated plates have been described previously (Yokota et al., 1989). LPS-coated plates were prepared according to the method of Pollack et al. (1987). Alkaline-phosphatase-conjugated goat anti-human IgM antibody (Kirkegaad \& Perry Laboratories) and sodium $p$-nitrophenyl phosphate were used as secondary antibody and substrate, respectively. Binding activity was expressed as $A_{405}$.

Statistical analysis. The one-factor ANOVA test was used to determine statistical significance of differences in blood clearance between $P$. aeruginosa TUM3 and TUM3 HSR or $S$. typhimurium LT2 and the LPS mutants.

\section{RESULTS}

\section{Complement killing microassay}

The results of the complement killing microassay are summarized in Table 2 . Over $99.9 \%$ of $P$. aeruginosa TUM3 was killed by $10 \%$ FHS in inoculum sizes of $10^{4}-10^{8}$ c.f.u. $\mathrm{ml}^{-1}$. TUM3 HSR completely resisted killing by $10 \%$ FHS. S. typhimurium LT2 (smooth LPS) was also resistant to $10 \%$ FHS. However, the degree of resistance was significantly influenced by inoculum size. LPS mutants derived from $S$. typhimurium LT2 were all sensitive to $10 \%$ FHS at all inoculum levels, with the highest sensitivity observed for the Re mutant TA2168. FMS did not kill any strain even when the serum concentration was increased to $90 \%$ (data not shown).

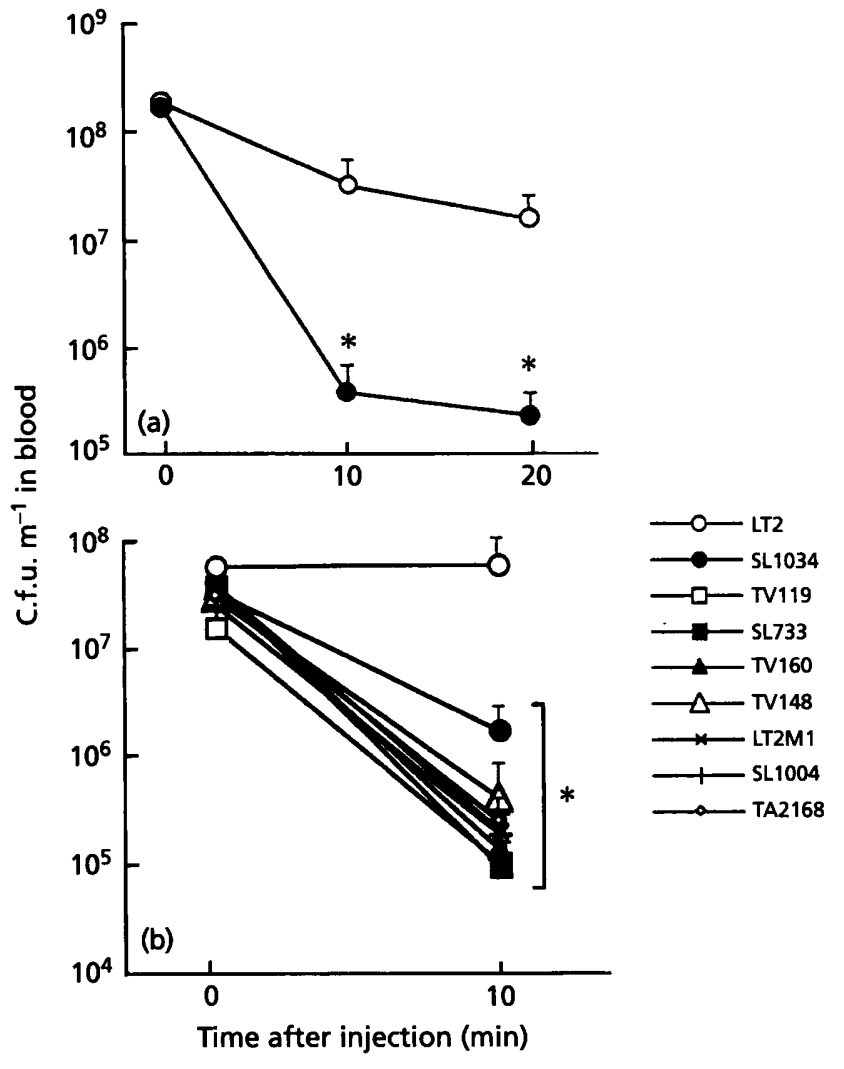

Fig. 1. Blood clearance rate in mice of (a) $P$. aeruginosa TUM3 (O) and TUM3 HSR (O), and (b) S. typhimurium LT2 and the LPS mutants (see figure for symbols). The experiments were repeated three times. A representative experiment is shown. Data shown are the mean and standard deviation from three animals. The differences between TUM3 and TUM3 HSR at time points of $10 \mathrm{~min}$ and $30 \mathrm{~min}$, and between $S$. typhimurium LT2 and the LPS mutants were statistically significant at $P<0.01$ (ANOVA).

\section{Blood clearance}

Fig. 1(a, b) shows the blood clearance rates in mice of different bacterial strains. $P$. aeruginosa TUM3 and $S$. typhimurium TA2168 were rapidly cleared from the blood, with the bacterial count diminishing $10 \mathrm{~min}$ after injection to $0.21 \%$ and $0.06 \%$ of the initial inoculum, respectively. The survival ratios of $P$. aeruginosa TUM3 HSR and $S$. typhimurium LT2 $10 \mathrm{~min}$ after injection, $17.8 \%$ and $97.6 \%$, respectively, were significantly higher than those of their isogenic strains.

The bacterial numbers trapped in the liver $10 \mathrm{~min}$ after injection are shown in Fig. 2 as the phagocytic index. The phagocytic indices of $P$. aeruginosa TUM3 and the $S$. typhimurium LPS mutants were 200-10000-fold higher than those of $P$. aeruginosa TUM3 HSR and S. typhimurium LT2.

\section{LPS profile}

Silver-stained LPS profiles of $P$. aeruginosa TUM3 and TUM3 HSR, and $S$. typhimurium LT2 and TA2168, are shown in Fig. 3. High molecular mass LPS species were 


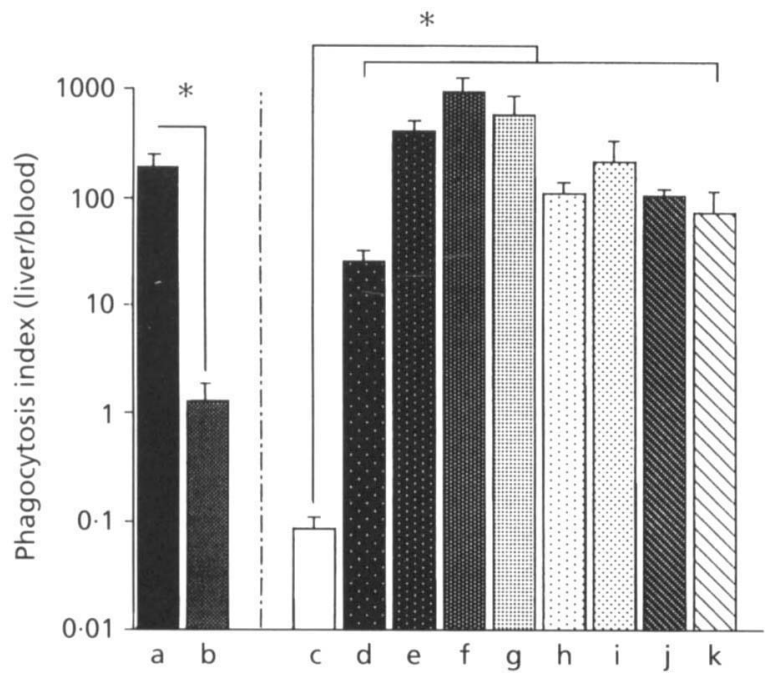

Fig. 2. Ratio of bacteria trapped in the liver to bacteria in the blood, $10 \mathrm{~min}$ after bacterial injection: a, $P$. aeruginosa TUM3; b, TUM3 HSR; c, S. typhimurium LT2; d, SL1034; e, TV119; $f$, SL733; g, TV160; h, TV148; i, LT2M1; j, SL1004; k, TA2168. Blood clearance and trapping in the liver were determined at the same time. Livers were removed immediately after blood was sampled. The experiments were repeated three times. A representative experiment is shown. Data shown are the mean and standard deviation from three animals. The differences between $P$. aeruginosa TUM3 and TUM3 HSR, and between LT2 and the LPS mutants, were statistically significant at $P<0.01$ (ANOVA).

expressed to a much greater extent in TUM3 HSR compared with the parent strain TUM3. The LPS profile of $S$. typhimurium LT2 and TA2168 showed typical bands of smooth and rough type (Re) LPS.

\section{Western blotting analysis}

Anti-serotype G O-polysaccharide mAb TK-5B12 specifically stained LPS derived from TUM3 as well as TUM3 HSR. However, the reaction was stronger in LPS of TUM3 HSR (Fig. 4a). Anti D-rhamnan mAb TS-1B2 specifically stained the position of A-band on the LPS molecules. The intensity of reaction was similar in TUM3 LPS and the TUM3 HSR LPS (Fig. 4b). Anti-serotype G core $\mathrm{mAb}$ OM-1D6 strongly stained LPS core region of TUM3 compared with that of TUM3 HSR (Fig. 4c).

\section{Binding of mAbs to P. aeruginosa TUM3 and TUM3 HSR cells}

The binding of TK-5B12 to TUM3 HSR was stronger than that to TUM3 (Fig. 5a). OM-1D6 strongly bound to TUM3, but showed little binding to TUM3 HSR (Fig. 5c). TS-1B2 bound to both TUM3 and TUM3 HSR with approximately similar intensity (Fig. 5b).

\section{Determination of complement $\mathrm{C} 3$ binding to the surface of bacteria}

The results from flow cytometry quantified the specific binding of an FITC-labelled anti-C3 $\mathrm{mAb}$ to the cell

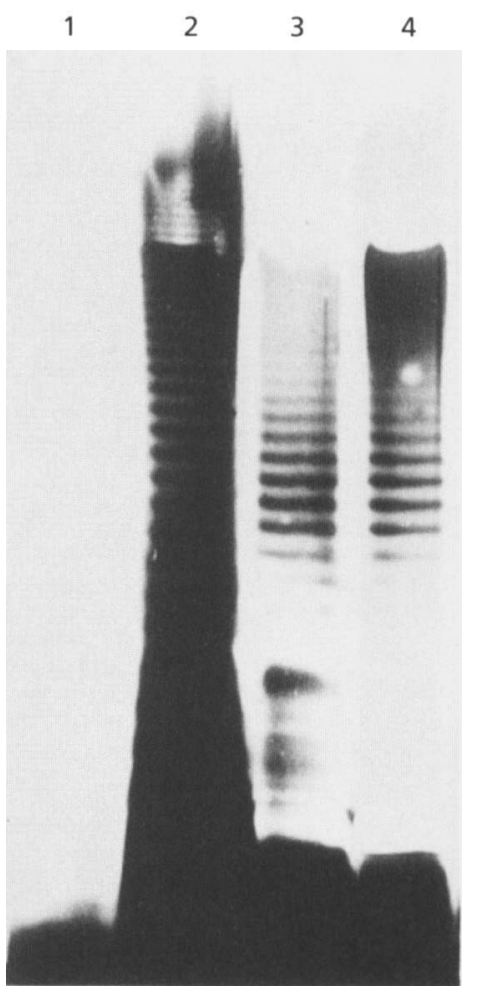

Fig. 3. Silver-stained SDS-PAGE $(12.5 \% \mathrm{gel})$ of LPS from $P$. aeruginosa TUM3 and TUM3 HSR, and S. typhimurium LT2 and LPS-deficient mutant TA2168. Lanes: 1 , S. typhimurium TA2168; 2 , S. typhimurium LT2; 3, P. aeruginosa TUM3; 4, P. aeruginosa TUM3 HSR.

surface of each bacterial strain. The level of $\mathrm{C} 3$ bound to the bacterial surface of the serum-sensitive strain was similar to that of the serum-resistant strains in both $P$. aeruginosa and $S$. typhimurium (data not shown).

\section{DISCUSSION}

The complement-mediated serum bactericidal system is an important factor limiting the invasion of the host by organisms colonizing the mucous membranes. Various surface antigens, such as LPS with long $\mathrm{O}$-polysaccharide chains, outer-membrane proteins (Heffernan et al., 1992) and capsules (Glynn \& Howard, 1970) render bacterial cells resistant to complement-mediated bactericidal killing. The profiles on silver-stained gels of LPS purified from the serum-sensitive $P$. aeruginosa TUM3 and its resistant derivative, TUM3 HSR, showed that a high molecular mass band was more strongly stained in TUM3 HSR, which was also confirmed by the results of Western blotting analysis and ELISA by anti-serotype $\mathrm{G} O$ polysaccharide $\mathrm{mAb}$ TK-5B12. The level of A-band (Drhamnan) on the LPS molecules from strain TUM3 HSR was approximately equal to that from strain TUM3. Interestingly, anti-serotype $\mathrm{G}$ core $\mathrm{mAb}$ OM-1D6 bound to the cell surface of strain TUM3 but not to that of strain TUM3 HSR although it specifically stained the core region on LPS molecules from both TUM3 and TUM3 HSR. These observations suggest that the long $\mathrm{O}-$ 


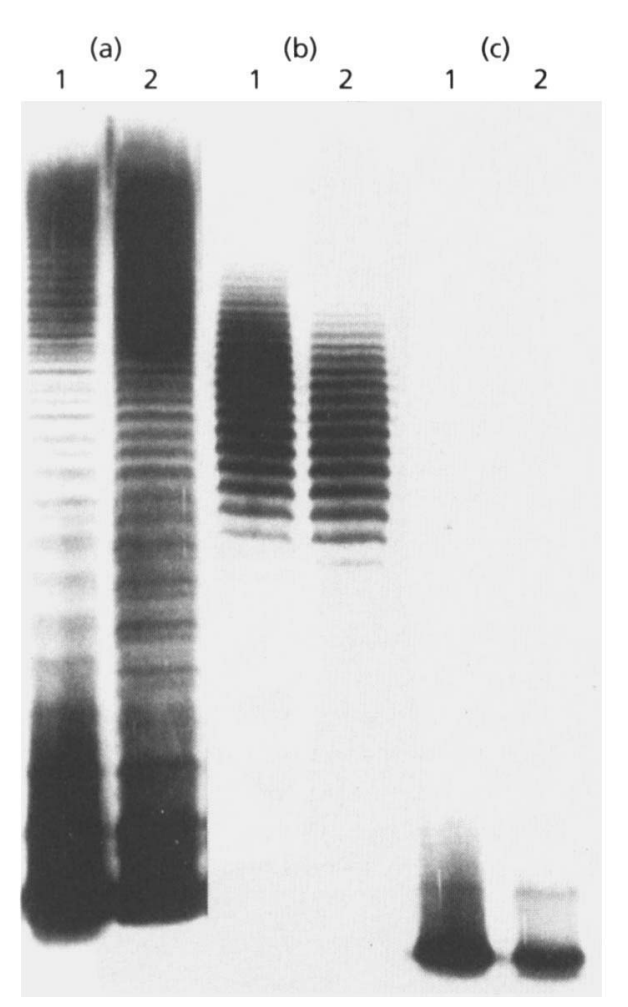

Fig. 4. Western blotting analysis of the LPS from $P$. aeruginosa TUM3 and TUM3 HSR with human mAbs. LPS preparations, which were treated with proteinase $K$, were derived from $P$. aeruginosa TUM3 (lanes 1) and TUM3 HSR (lanes 2). Immunoblots with (a) TK-5B12 (anti-serotype G Opolysaccharide mAb), (b) TS-1B2 (anti-D-rhamnan MAb) and (c) OM-1D6 (anti-serotype G core region mAb).

polysaccharide molecules were overproduced in this derivative, and therefore, anti-core mAb OM-1D6 was not capable of accessing the core LPS region on the cell surface of strain TUM3 HSR. Furthermore, no change was observed in the outer-membrane proteins on TUM3 HSR compared with the serum-sensitive parent strainTUM3 (data not shown).

Most $P$. aeruginosa strains isolated from patients with $\mathrm{CF}$ are sensitive to the serum bactericidal system. This is due to a deficiency of long O-polysaccharides on their LPS molecules. However, human-serum-sensitive strain TUM3 possessed serotype $\mathrm{G}(\mathrm{O} 6) \mathrm{O}$-antigen. Dasgupta et al. (1994) recently compared the serum sensitivity of a serotype O5 strain with that of a serotype O6 strain. Whereas the serotype $\mathrm{O} 5$ strain was completely resistant to the human serum bactericidal system, the serotype $\mathrm{O} 6$ strain was partially resistant. These investigators demonstrated that the B-band LPS molecules of the O5 strain formed an extensive fibrosis coat on the outer leaflet of the outer membrane, while the B-band LPS of the O6 strain could be discerned only as patches of fibrotic material on the bacterial surface, and suggested that the distribution of LPS molecules bearing the long $\mathrm{O}$-antigen side chains influences the serum sensitivity. In the present study, the profiles on silver staining, Western blotting analysis and
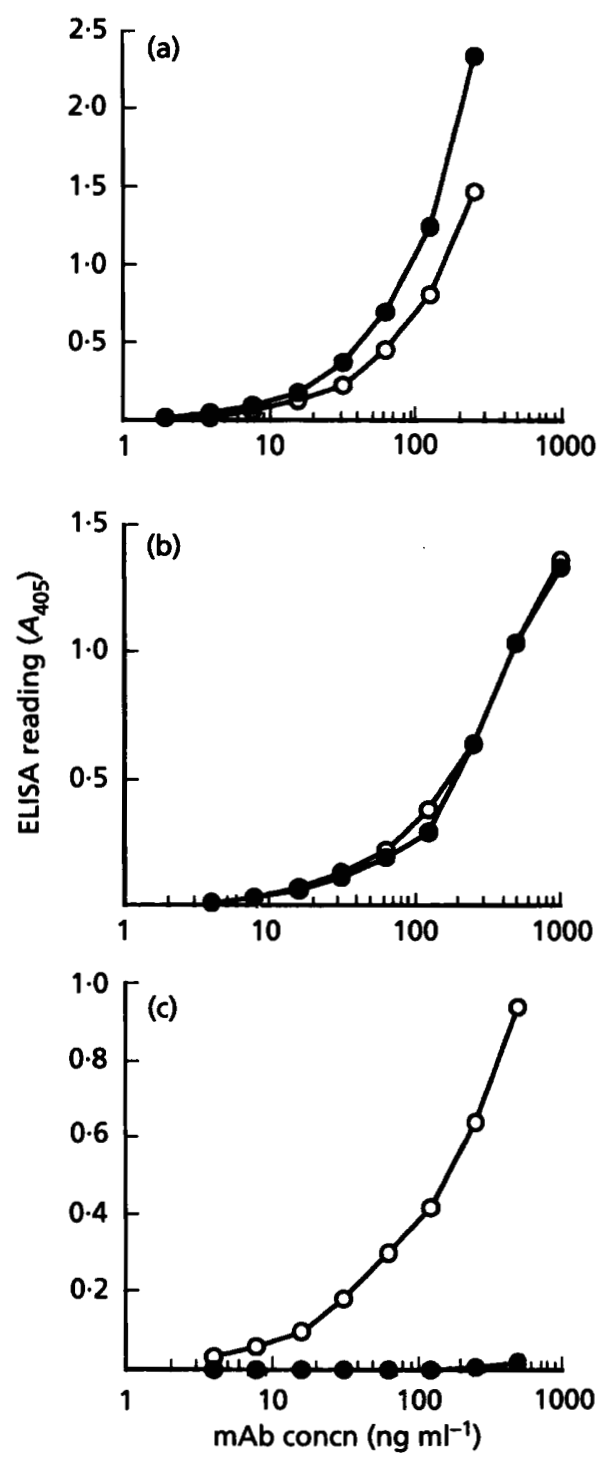

Fig. 5. Binding of (a) anti-serotype G O-polysaccharide mAb TK5B12, (b) anti-D-rhamnan mAb TS-1B2 and (c) anti-serotype G core region mAb OM-1D6 to $P$. aeruginosa TUM3 $(O)$ and TUM3 HSR (O). Binding activity was determined by ELISA using plates coated with whole cells of each strain and expressed as $A_{405}$.

ELISA demonstrated a poor expression of long Opolysaccharide molecules on the LPS from strain TUM3. Therefore, a major determinant of serum resistance in TUM3 HSR appeared to be an overproduction of a long O-polysaccharide side chain on the LPS molecule.

Comparison of the blood clearance rate in mice indicated that strain TUM3 was eliminated more rapidly than strain TUM3 HSR. However, the murine serum used in this study was not capable of killing strain TUM3, even when the serum concentration was $90 \%$ (data not shown). Furthermore, murine serum could not kill either $S$. typhimurium LT2 or LPS-deficient mutants of this strain. S. typhimurium LPS-deficient mutants were also more rapidly eliminated from the blood of mice compared with 
strain LT2. Inoue (1972) has described the mouse complement system as immature, due to negligible serum bactericidal activity compared with nonhuman primates and humans. These results point to the existence of mechanisms other than serum killing that limit the spread into the bloodstream of bacteria lacking or having decreased long O-polysaccharide on their LPS molecules.

On the other hand, the number of $P$. aeruginosa TUM 3 and S. typhimurium LT2 LPS-deficient mutants trapped in the liver 10 min after injection was higher than that of their respective counterparts. This finding indicates that the loss or decrease of long O-polysaccharide molecule renders the bacteria sensitive to serum bactericidal systems and also facilitates trapping by the RES. Consequently, the systemic spread of these strains becomes significantly limited.

An inhibitor of the synthesis of KDO heptose, which constitutes the inner core of the LPS, enhances the rate of bacterial clearance from mouse blood (Hammond, 1992), further indicating that bacteria lacking long O-side chains are readily cleared from the bloodstream. In the present study, however, experiments using smooth-LPS-type $S$. typhimurium LT2 and a series of LPS-deficient mutants with gradually diminishing length of $\mathrm{O}$ - or core-polysaccharide side chain revealed that rapid elimination from the bloodstream occurred even with strain SL1034 [rfe (SR) mutant], which has an O-side chain of only one repeating unit, but the longest LPS among the mutant strains studied. This result demonstrated that the presence of more than at least one repeating unit of the $\mathrm{O}$ polysaccharide was important in protecting against early clearance from the bloodstream. It is, of course, clear that the structure of LPS side chain in P. aeruginosa is different from that of $S$. typhimurium. The serum-resistant property of $S$. typhimurium LT2 was significantly less than that of $P$. aeruginosa TUM3 HSR, suggesting that the difference in the chemical structure of the polysaccharide side chain may also influence the sensitivity to serum bactericidal systems (Grossmann \& Leive, 1984). It is, however, not established whether such differences in structure play a part in the clearance rate from the bloodstream.

The initial stage of bacterial phagocytosis involves the attachment of bacteria to complement receptors, such as CR1 and integrin $\alpha_{\text {mac }} \beta 2$ (CR3) (Speert, 1993). These receptors recognize complement fragments $\mathrm{C} 3 \mathrm{~b}$ and $\mathrm{iC} 3 \mathrm{~b}$, respectively. C3 attaches both to the Fc portion of antibody, and to LPS. These complement receptors can also bind directly to LPS on nonopsonized bacteria (Wright \& Jong, 1986). If the level of binding of C3 components to bacterial cell surfaces is higher in strains with short O-side chains on their LPS compared with strains with long O-side chains on their LPS, it would be expected that the LPS mutants would be cleared more easily from the bloodstream. However, flow-cytometry results demonstrated that murine $\mathrm{C} 3$ binding to bacterial cells was almost equal among the isogenic sets: $P$. aeruginosa TUM3 and TUM3 HSR, and S. typhimurium LT2 and $r f a(\mathrm{Re})$ mutant TA2168, with the shortest LPS molecule. These results are inconsistent with those reported by Schiller \& Joiner (1986) demonstrating that the $P$. aeruginosa mucoid strain $144 \mathrm{M}$ with a short-sidechain LPS was able to bind C3 twice as much as $P$. aeruginosa mucoid strain 144M SR (derived from 144M) with long $\mathrm{O}$-side chains. These investigators suggested that the binding site of C3 to LPS was hindered by long O-side chains on the 144M SR LPS. On the other hand, Joiner et al. (1982a, b) reported that twice as many molecules of radiolabelled $\mathrm{C} 3$ were bound per cell of an $S$. minnesota smooth LPS strain compared with a mutant strain having only core-LPS. They also reported that the membrane attack complex formed more rapidly on LPS smooth strains, but the binding of $\mathrm{C} 3$ to the long O-side chains was unstable and $\mathrm{C} 3$ was released easily from the LPS chain.

Based on these results, another mechanism could also be considered. The LPS-binding protein (LBP), that exists in a concentration of 5-10 $\mu \mathrm{g}$ per $\mathrm{ml}$ of blood (Mathison $e t$ al., 1993), binds with a high affinity to LPS via lipid A (Schumann et al., 1990). The LPS-LBP complex in turn binds to CD14 expressed on the surface of phagocytic cells. Since macrophages tend to bind LPS-LBP complexes rather than free LPS, it is possible that LPS with short side chains or only the core region bind better to LBP. Such a scenario is possible since lipid A, a target of LBP, is exposed in strains with a short-side-chain LPS. Furthermore, phagocytic cells express low levels of CD14 and CR3, but the level increases substantially in response to LPS (Weingarten et al., 1993). Thus, it is important to examine the expression level of CD14 and CR3 following exposure to LPS isolated from each strain. On the other hand, we must consider that receptors on macrophages directly bind to LPS. Furthermore, these receptors preferentially bind to short-side-chain LPS rather than to smooth LPS. Current studies are attempting to define these potential mechanisms further.

\section{ACKNOWLEDGEMENTS}

The authors are grateful to Professor T. Sawai and Dr M. I. Marks for kindly providing different bacterial strains. They also thank Dr F. G. Issa (Word-Medex) for his assistance in reading and editing the manuscript.

\section{REFERENCES}

Arsenault, T. L., Hughes, D. W., Maclean, D. B., Szarek, W. A., Kropinski, A. M. B. \& Lam, J. S. (1991). Structural studies on the polysaccharide portion of 'A-band' lipopolysaccharide from a mutant (AK1401) of Pseudomonas aeruginosa strain PAO1. Can $J$ Chem 69, 1273-1280.

Coyne, M. J., Jr, Russell, K. S., Coyle, C. L. \& Goldberg, J. B. (1994). The $P$ seudomonas aeruginosa alg $C$ gene encodes phosphoglucomutase, required for the synthesis of a complete lipopolysaccharide core. $J$ Bacteriol 176, 3500-3507.

Darveau, R. P. \& Hancock, R. E. W. (1983). Procedure for isolation of bacterial lipopolysaccharide from both smooth and rough Pseudomonas aeruginosa and Salmonella typhimurium strains. J Bacteriol 155, 831-838.

Dasgupta, T., Kievit, T. R., Masoud, H., Altman, E., Richards, J. C., Sadovskaya, I., Speert, D. P. \& Lam, J. S. (1994). Characterization 
of lipopolysaccharide-deficient mutants of Pseudomonas aeruginosa derived from serotypes O3, O5, and O6. Infect Immun 62, 809-817.

Glynn, A. A. \& Howard, C. J. (1970). The sensitivity to complement of strains of Escherichia coli related to their $\mathrm{K}$ antigens. Immunology 18, 331-346.

Grossmann, N. \& Leive, L. (1984). Complement activation via the alternative pathway by purified Salmonella lipopolysaccharide is affected by its structure but not its O-antigen length. J Immunol 132, 376-385.

Hammond, S. M. (1992). Inhibitors of lipopolysaccharide biosynthesis impair the virulence potential of Escherichia coli. FEMS Microbiol Lett 100, 293-298.

Hatano, K., Goldberg, J. B. \& Pier, G. B. (1993). Pseudomonas aeruginosa lipopolysaccharide: evidence that the $\mathrm{O}$ side chains and common antigens are on the same molecule. $J$ Bacteriol 175, 5117-5128.

Heffernan, E. J., Reed, S., Hackett, J., Fierer, J., Roudier, C. \& Guiney, D. (1992). Mechanism of resistance to complementmediated killing of bacteria encoded by the Salmonella typhimurium virulence plasmid gene rck. J Clin Invest 90, 953-964.

Inoue, K. (1972). Immune bacteriolytic and bactericidal reaction. In Research in Immunochemistry and Immunobiology, vol. 1, pp. 177-222. Edited by J. B. G. Kwapinski. Baltimore: University Park Press.

Joiner, K. A., Hammer, C. H., Brown, E. J., Cole, R. J. \& Frank, M. M. (1982a). Studies on the mechanism of bacterial resistance to complement-mediated killing. I. Terminal components are deposited and released from Salmonella minnesota S218 without causing bacterial death. $J$ Exp Med 155, 797-808.

Joiner, K. A., Hammer, C. H., Brown, E. J. \& Frank, M. M. (1982b). Studies on the mechanism of bacterial resistance to complementmediated killing. II. C8 and C9 release C5b67 from the surface of Salmonella minnesota S218 because the terminal complex does not insert into the bacterial outer membrane. J Exp Med 155, 809-819.

Lam, M. Y. C., McGroarty, E. J., Kropinski, A. M., Macdonald, L. A., Pederson, S. S., Høiby, N. \& Lam, J. S. (1989). Occurrence of a common lipopolysaccharide antigen in standard and clinical strains of Pseudomonas aeruginosa. J Clin Microbiol 27, 962-967.

Leunk, R. D. \& Moon, R. J. (1982). Association of type 1 pili with the ability of livers to clear Salmonella typhimurium. Infect Immun 36, 1168-1174.

Lindberg, A. A. \& Hellerqvist, C. G. (1971). Bacteriophage attachment sites, serological specificity, and chemical composition of the lipopolysaccharides of semirough and rough mutants of Salmonella typhimurium. J Bacteriol 105, 57-64.

Mathison, J., Wolfson, E., Steinemann, S., Tobias, P. \& Ulevitch, R. J. (1993). Lipopolysaccharide (LPS) recognition in macrophages: participation of LPS-binding protein and CD14 in LPS-induced adaptation in rabbit peritoneal exudate macrophages. $J$ Clin Invest 92, 2053-2059.

Merino, S., Camprubi, S., Alberti, S., Benedi, V. J. \& Tomas, J. M. (1992). Mechanisms of Klebsiella pneumoniae resistance to complement-mediated killing. Infect Immun 60, 2529-2535.

Ohno, A., Miyazaki, S., Tateda, K., Kaneko, Y., Huruya, N., Tsuji, A. Yamaguchi, K. \& Goto, S. (1992). The study of pathogenic mechanisms of chronic Pseudomonas aeruginosa lung infections by mucoid strains. J Jpn Assoc Infect Dis 66, 408-415.

Palomar, J., Montilla, R., Fuste, M. C. \& Vinas, M. (1993). The role of O-antigen in susceptibility of Serratia marcescens to non-immune serum. Microbios 76, 189-196.

Pollack, M., Raubitschek, A. A. \& Larrick, J. W. (1987). Human monoclonal antibodies that recognize conserved epitopes in the core-lipid A region of lipopolysaccharides. J Clin Invest 79, $1421-1430$

Rivera, M. \& McGroarty, E. J. (1989). Analysis of a common antigen lipopolysaccharide from Pseudomonas aeruginosa. $J$ Bacteriol 171, 2244-2248.

Rivera, M., Bryan, L. E., Hancock, R. E. W. \& McGroarty, E. J. (1988). Heterogeneity of lipopolysaccharides from Pseudomonas aeruginosa: analysis of lipopolysaccharide chain length. $J$ Bacteriol 170, 512-521.

Roantree, R. H., Kuo, T. T. \& Macphee, D. G. (1977). The effect of defined lipopolysaccharide core defects upon antibiotic resistances of Salmonella typhimurium. J Gen Microbiol 103, 223-234.

Schiller, N. L. \& Hatch, R. A. (1983). The serum sensitivity, colonial morphology, serogroup specificity, and outer membrane protein of Pseudomonas aeruginosa strains isolated from several clinical sites. Diagn Microbiol Infect Dis 1, 145-157.

Schiller, N. L. \& Joiner, K. A. (1986). Interaction of complement with serum-sensitive and serum-resistant strains of Pseudomonas aeruginosa. Infect Immun 54, 689-694.

Schiller, N. L., Hackly, D. R. \& Morrison, A. (1984). Isolation and characterization of serum-resistant strains of Pseudomonas aeruginosa derived from serum-sensitive parental strains. Curr Microbiol 10, 185-190.

Schumann, R. R., Leong, S. R., Flaggs, G. W., Gray, P. W., Wright, S. D., Mathison, J. C., Tobias, P. S. \& Ulevitch, R. J. (1990). Structure and function of lipopolysaccharide binding protein. Science 249, 1429-1431.

Speert, D. P. (1993). Phagocytosis of Pseudomonas aeruginosa by macrophages: receptor-ligand interactions. Trends Microbiol 1, 217-221.

Taylor, P. W. (1983). Bactericidal and bacteriolytic activity of serum against gram-negative bacteria. Microbiol Rev 47, 46-83.

Thomassen, M. J. \& Demko, C. A. (1981). Serum bactericidal effect on Pseudomonas aeruginosa isolates from cystic fibrosis patients. Infect Immun 33, 512-518.

Yokota, S., Ochi, H., Ohtsuka, H., Kato, M. \& Noguchi, H. (1989). Heterogeneity of the L-rhamnose residue in the outer core of Pseudomonas aeruginosa lipopolysaccharide, characterized by using human monoclonal antibodies. Infect Immun 57, 1619-1696.

Yokota, S., Kaya, S., Araki, Y., Ito, E., Kawamura, T. \& Sawada, S. (1990). Occurrence of D-rhamnan as the common antigen reactive against monoclonal antibody E87 in Pseudomonas aeruginosa IFO 3080 and other strains. $J$ Bacteriol 172, 6162-6164.

Weingarten, R. L. A. , Sklar, J. C. M., Omidi, S., Ainsworth, T., Simon, S., Ulevitch, R. J. \& Tobias, P. S. (1993). Interactions of lipopolysaccharide with neutrophils in blood via CD14.J Leukocyte Biol 53, 518-524.

Wright, S. D. \& Jong, M. T. C. (1986). Adhesion-promoting receptors on human macrophages recognize $E$. coli by binding to lipopolysaccharide. J Exp Med 164, 1876-1888.

Received 22 June 1995; accepted 30 June 1995. 